\title{
Informes
}

\section{Reseña del seminario "El proceso de la reforma migratoria en Estados Unidos y sus implicaciones para México y Estados Unidos"}

\section{Eduardo Torre Cantalapiedra*}

La novena sesión del Seminario Permanente sobre Migración Internacional (Sepmig) de 2013 abordó el tema del proceso de la reforma migratoria en Estados Unidos y sus implicaciones para México y Estados Unidos, ${ }^{1}$ y fue moderada por Silvia E. Giorguli Saucedo. La sesión tuvo dos objetivos: por un lado, presentar y discutir los elementos más recientes que conforman el debate en torno a dicho proceso; por otro, realizar un análisis binacional de las implicaciones de la reforma migratoria para los dos países y la región, para lo cual la sesión contó con dos panelistas: James Hollifield y Francisco Alba, uno de cada país. La presentación de Hollifield llevó como título "E pluribus unum: The Politics of Immigration Reform"; la de Alba, "El proceso de la reforma migratoria en Estados Unidos: una perspectiva desde México".

La composición del panel, con especialistas de ambos lados de la frontera, permitió al auditorio conocer los principales argumentos y perspectivas prevalecientes en Estados Unidos y en México sobre la reforma migratoria estadounidense. Los expositores realizaron sus análisis desde perspectivas tanto históricas como coyunturales, recuperando así diversos elementos que condujeron a un adecuado enten-

* Estudiante del doctorado en Estudios de Población de El Colegio de México. Correo electrónico: <etorre@colmex.mx>.

${ }^{1}$ La novena sesión tuvo lugar el 7 de noviembre de 2013 en El Colegio de México. El Seminario Permanente sobre Migración Internacional (Sepmig) fue fundado por El Colegio de la Frontera Norte en noviembre de 1998 con la colaboración de El Colegio de México y la Sociedad Mexicana de Demografía, y posteriormente, en 2004, con la organización Sin Fronteras. En el ciclo actual la base institucional de este seminario está constituida por El Colegio de la Frontera Norte, el Centro de Investigaciones y Estudios Superiores en Antropología, El Colegio de México, El Colegio de Michoacán, El Colegio de la Frontera Sur, el Instituto de Investigaciones Dr. José María Luis Mora, el Instituto de Investigaciones Sociales de la UNAM, la Sociedad Mexicana de Demografía, la Universidade da Coruña y la University of California Los Angeles. El Sepmig se ha convertido en un referente para académicos y especialistas en el campo de las migraciones internacionales. El seminario se ha podido seguir por videoconferencia en otras instituciones regionales y por internet. 
dimiento del intrincado proceso de la reforma, así como de los debates actuales al respecto, incluyendo el relativo al papel de México en este proceso.

El doctor James Hollifield situó los debates actuales sobre migración en Estados Unidos en un marco histórico amplio, lo que favoreció un mejor esclarecimiento de los mismos. Como especialista en ciencia política resaltó las condiciones legales y políticas, las políticas públicas y la importancia de los derechos humanos como elementos necesarios para entender las migraciones internacionales. En los siguientes párrafos se recogen algunas de las principales ideas que el politólogo plasmó en la ponencia.

Hollifield inició su presentación con una interpretación de la frase $E$ pluribus unum (de muchos se hizo uno), aludiendo a que de muchos pueblos, razas, religiones y ancestros emerge un solo pueblo y una sola nación. Para él, esta expresión permite entender mejor los debates actuales. A lo largo de la historia de Estados Unidos ha existido una preocupación por el unum (el uno), y en otras ocasiones ha habido más aceptación de los pluribus (los muchos). Hay en la actualidad un equilibrio incómodo entre ambos extremos, pues a pesar de que Estados Unidos es un país diverso y tolerante, existe una gran preocupación respecto del unum.

Pensar el debate migratorio en términos de los pluribusy del unum, le permitió a Hollifield esquematizar el debate actual teniendo como referentes los tres modelos migratorios surgidos en la época de "las colonias americanas". Primero, el modelo de Massachusetts, que básicamente es puritano y del ideal WASP (White Anglo-Saxon and Protestant), conforme al cual los inmigrantes pueden venir pero deben pensar y creer lo mismo que los puritanos. Segundo, el modelo de Virginia, que no se preocupa por la religión e ideas de los inmigrantes ni de quiénes son éstos, sino que busca trabajadores que no necesariamente deben integrarse a la comunidad. El ejemplo paradigmático en la historia de las migraciones de México hacia Estados Unidos es el programa bracero. Tercero, el modelo de Pennsylvania, la colonia de los cuáqueros, según el cual los inmigrantes pueden venir y trabajar, y si aceptan las leyes y las normas de la república entonces pueden llegar a formar parte de la nación.

Hollifield se preguntó: ¿qué modelo prevalecerá en el siglo XXI? y planteó la importancia de los derechos a partir de la Segunda Guerra Mundial para entender los actuales debates sobre la migración. Destacó la constitución de una coalición derechos-mercados (entre los libe- 
rales de izquierda que buscan extender los derechos y los republicanos de derecha, orientados a los negocios, que promueven la expansión de los mercados) que facilitó la aprobación de IRCA en 1986. Sin embargo IRCA no logró los objetivos de esta coalición dado el peso de la inmigración indocumentada (generada por una demanda de visas muy superior a la oferta) en los flujos migratorios hacia Estados Unidos y la generación de una nueva subclase social de personas que viven fuera de la ley y en las sombras.

Acotando la temporalidad hacia el presente, Hollifield realizó un análisis de ciertos elementos relevantes de tipo coyuntural, entre los que destacó tres eventos como fundamentales para encuadrar el debate actual: el primero, la Proposición 187 en California como resultado de los temores generados por los altos niveles de inmigración, especialmente la ilegal, que podrían entenderse como un miedo de tipo cultural a que la cifra de inmigrantes sea excesiva; el segundo, el 11 de septiembre, que supone que la seguridad se convierta en el paradigma dominante; el tercero, la propuesta de Sensenbrenner que pretendía que los inmigrantes fueran considerados criminales y que generó una enérgica respuesta de la sociedad. Dados estos tres eventos, la coalición derechos-mercados cae, y en 1996 se aprueba una legislación que produce una reversión de los derechos sociales y civiles de los migrantes.

Para Hollifield los paradigmas dominantes en las políticas de control son la economía en los años 1980, la cultura en los 1990 y la seguridad en la primera década del siglo XXI. En esta evolución, dada la escisión de la coalición derechos-mercados, ¿puede darse una nueva coalición entre republicanos y demócratas en la materia migratoria? Es difícil, debido al auge de la derecha radical que ha supuesto el auge legislativo de los estados (Arizona, Alabama, etc.) y a las políticas locales.

En un país crecientemente diverso debido a la inmigración, otro aspecto de la coyuntura que remarca el politólogo es el resurgimiento del "voto étnico", que apoyó mayoritariamente al presidente Obama en su elección en 2008 y su reelección en 2012 y que fue clave en los estados swing.

Finalmente, Hollifield aludió directamente a los debates actuales. Según el investigador, éstos están conformados por dos bandos: el de aquellos que desean una reforma inmigratoria comprensiva y el de aquellos que desean una reforma que se enfoque en el enforcement. Concluyó que la inmigración sigue siendo una pieza fundamental en 
la economía de Estados Unidos, país que debe hacer frente a la "paradoja liberal" de estar abierto a los inmigrantes como mano de obra necesaria para el desarrollo económico y al mismo tiempo cerrado a los mismos para no socavar el contrato social. En este sentido cobran una gran importancia el estatus y los derechos de los inmigrantes.

En su presentación Francisco Alba abordó la coyuntura más reciente del proceso de la reforma migratoria; destacó el papel de los agentes y estructuras intervinientes en el mismo, a la vez que revisó algunas explicaciones analíticas sobre el proceso, deteniéndose en las vicisitudes por las que ha transitado y que en buena medida explican la dificultad del proceso de la reforma. Además, el investigador dedicó parte de su ponencia al debate sobre el papel de México en este proceso y a las implicaciones del mismo para este país.

Alba se refirió inicialmente a los principales actores de la reforma migratoria y a algunas de sus principales acciones al respecto; por un lado, el Poder Ejecutivo, que ha planteado la necesidad de una "reforma migratoria integral"; por otro, un Congreso dividido no sólo entre líneas partidistas y entre sus miembros, sino entre sus dos órganos: el Senado y "la Cámara de Representantes". Así, por un lado el Senado pasó una iniciativa que incorporó múltiples elementos de una reforma integral: el fortalecimiento de la seguridad fronteriza; la satisfacción a los requerimientos del mercado laboral con programas de trabajadores temporales o con la facilitación de la migración calificada; y la regularización de la población en situación irregular, incluyendo vías a la ciudadanía de dicha población. Por su lado, la estrategia de la House of Representatives ha sido la de presentar múltiples iniciativas, es decir, proceder tópico por tópico, dado que la idea es avanzar en aquello en lo que estén de acuerdo los diferentes grupos. Además hay otros actores importantes, como los estados y las organizaciones sociales, que tienen posturas y frentes diversos. Alba resumió la situación actual (al 7 de noviembre de 2013) de la siguiente manera: existe un gran activismo por parte de los diversos actores, una gran incertidumbre sobre lo que puede suceder, y un estancamiento del proceso.

Para un mejor entendimiento de la situación Alba recurrió a diversos marcos analíticos. Desde la óptica del realismo político y el juego de intereses, el investigador concluyó que el peso de los intereses de los agentes "hispanos" y "pro-inmigrantes" -creciente después de la elección por el apoyo a Obama en 2012- parece estar diluyéndose, mientras que sus adversarios parecen recuperar el peso ganado con anterioridad al cobrar importancia el paradigma de la seguridad y la 
creación del Department of Homeland Security (DHS). Desde el marco analítico del desempeño de las instituciones y de los agentes o actores, el aparente equilibrio de los diversos intereses en conflicto parecería conducir a situaciones de semiparálisis (situación de stalemate). Alba hizo notar la ausencia en la discusión de consideraciones sobre las relaciones internacionales y los factores de geopolítica; esto es, parece que en el proceso interno no se tienen en cuenta ni a México ni a la región. Por último, sostuvo que las perspectivas sobre la evolución futura de los factores económicos -que por el momento permanecen estables- también influyen en las percepciones que terminan por modelar los diferentes intereses.

Alba se refirió a las expectativas que se generaron seis meses antes, cuando se presentó una coyuntura especialmente favorable para que se materializara una amplia reforma. Al respecto, recordó que en un momento advirtió sobre las vicisitudes que podrían presentarse antes de que pudiera lograrse una reforma, y sobre lo azaroso que podría ser todo el proceso. Para el investigador, el momentum migratorio se ha ido diluyendo a medida que asuntos diversos (como la elevación del techo de la deuda pública) han tenido capturadas tanto la agenda legislativa como la del Ejecutivo, en un contexto de debilitamiento del presidente Obama. Alba también mencionó que en el proceso legislativo, complicado per se, se presentaron mayores resistencias a la reforma que las previstas y, como conclusión a esta parte, planteó que los posibles resultados del proceso de la reforma son en la actualidad todavía más inciertos que seis meses antes.

A continuación expuso los principales ejes del debate sobre el papel de México en este proceso. En su opinión "la cuestión migratoria" no parece ser un asunto prioritario de la agenda bilateral, ni para Estados Unidos ni para México -si bien la postura mexicana sobre temas migratorios mantiene una gran presencia en la agenda global-. Según Alba, la presencia y la visibilidad del tópico migratorio en los medios de opinión pública del país son mayores que en los medios de discusión académica y en los medios decisorios de política pública. En los primeros hay una serie de llamados a una participación más activa del país en el debate y el quehacer político estadounidenses, al tiempo que el proceso interno de "desmigratización" de la relación bilateral continúa su curso. Para Alba esta evolución es hasta cierto punto entendible, dado que la relación bilateral es más trascendente que la cuestión migratoria. Sin embargo, el papel del Estado en cuanto a la gestión migratoria es cada vez más definitorio del carácter del Estado 
mismo, aludiendo al concepto -desarrollado por Hollifield-del "estado migratorio" (migration state).

Alba afirmó que la agenda migratoria gubernamental mexicana parecería estar supeditada a que se alcance una "reforma migratoria comprehensiva", y que hay preparativos mexicanos ante una eventual regularización, como el fortalecimiento de la red consular. Expuso algunas consideraciones que condicionan que el papel de México sea mayor. Según el investigador México ha perdido, especialmente desde septiembre 11 de 2011, grados de libertad de acción o posibilidades de negociación con Estados Unidos. En general el entorno se ha vuelto muy adverso para una continuidad no conflictiva del fenómeno migratorio, si bien parece haber cambiado ante una migración neta cercana a cero donde la migración indocumentada ha disminuido sensiblemente. Además está la gran incertidumbre sobre la adopción, el contenido y las implicaciones de la reforma migratoria. Así mismo, Alba destacó la dinámica de una multidimensional interpenetración regional -desde Canadá hasta Centroamérica- que no cuenta con proyectos políticos de integración regional de largo aliento y alcance (más allá de la creación de áreas de libre comercio con propósitos de "competitividad regional"), por lo que la movilidad laboral y humana se da en ausencia de proyectos de integración regional compartidos.

Alba enunció que las respuestas mexicanas del futuro van a tener que moverse entre los tres tipos de políticas migratorias del pasado: "la política de no tener política"; las políticas reactivas (frente a decisiones tomadas en Estados Unidos); y la política de la iniciativa (lo que sucedió brevemente cuando México dictó la agenda migratoria a principios del año 2001, episodio que acabó tras septiembre 11).

Por lo que se refiere a las implicaciones para México de las iniciativas de "reforma migratoria", Alba señaló que se deben analizar con detalle los diversos aspectos de todas las iniciativas, incluidas las denominadas "comprehensivas". Así, el control fronterizo es un elemento ineludible de cualquier reforma, lo que podría afectar en forma adversa a volúmenes cuantiosos de potenciales migrantes mexicanos -claro, sin autorización-. La satisfacción de las necesidades de los mercados laborales estadounidenses tiende a privilegiar los programas de trabajadores temporales y la facilitación del acceso o de la permanencia de migrantes cualificados, todo lo cual podría derivar en una creciente selectividad positiva de los emigrantes mexicanos. En este sentido, ante la selectividad migratoria México tendría que buscar, por un lado, la circularidad de dichos migrantes, y, por 
otro, defender espacios para que se satisfagan los requerimientos migratorios de las familias mexicanas. Incluso la regularización de los inmigrantes en situación irregular presenta interrogantes de gestión sobre los plazos del proceso, su selectividad, y el estatus final al que sea posible acceder.

Finalmente, Alba sugirió algunos ejes orientadores para la construcción de una nueva agenda migratoria para México. Planteó, por un lado, buscar la retención de la población en el territorio por medio del desarrollo económico, social y político del país; por otro, fomentar una migración segura, ordenada, legal y exitosa; además, mantener un papel activo y multidimensional de la política y la diplomacia mexicanas frente a las multifacéticas "cuestiones migratorias", incluidas la defensa de los mexicanos en el exterior y la búsqueda de regímenes migratorios internacionales estables. Finalmente sostuvo que la búsqueda de gobernabilidad no es una tarea tan solo ante la emigración de mexicanos, sino también ante la migración de tránsito (porosidad de la frontera sur y el trato a los migrantes), el retorno y las deportaciones, y ante la inmigración.

Tras las ponencias se pasó a una ronda de preguntas y respuestas sobre los diversos temas expuestos por los ponentes. Sobre las preguntas que se centraron en la evolución de la política estadounidense, se resaltó que el colapso de la coalición derechos-mercados se debió particularmente al fin de la Guerra Fría y a las tendencias al aislacionismo que surgieron tras ella. También se señaló que el cambio en el paradigma dominante -de lo económico hacia la seguridad- ha hecho que el "factor TLCAN" (Tratado de Libre Comercio de América del Norte) esté ausente en los debates migratorios actuales. Hollifield anotó específicamente que en su opinión las políticas de control en la frontera iniciadas por Bill Clinton respondieron a la idea de que si se demostraba tener el control sobre el fenómeno migratorio, las políticas inmigratorias podrían ser más aperturistas a través de cauces legales. También recordó que la reforma migratoria en Estados Unidos se entiende como algo que ha de resolverse de manera unilateral.

Sobre las preguntas que se enfocaron en la evolución de la política mexicana y el papel de México, Alba describió como destacadas algunas de las acciones que México ha llevado a cabo respecto a la protección de los migrantes en Estados Unidos a raíz de septiembre 11, tales como la acelerada y expedita expedición de las matrículas consulares. También calificó como positivo el reposicionamiento de la postura mexicana ante la nueva situación, reposicionamiento elabora- 
do años después, entre 2005 y 2006, y en el que se adoptó el término "responsabilidad compartida".

Alba puntualizó que la "nueva narrativa migratoria" alude al cambio que se está dando en los debates migratorios del país, los cuales ya no sólo versan sobre la emigración de México a Estados Unidos, sino sobre la inmigración, la migración de tránsito y el retorno; y cómo todos estos debates se interrelacionan. Ante los varios cuestionamientos sobre la Ley de Migración de 2011, planteó que es comprensible cierto desaliento sobre la efectividad de las nuevas medidas introducidas, máxime frente a posturas retóricas que aluden al logro de determinados resultados que en realidad aún están por materializarse. 